\title{
CONCEPT AND MANAGEMENT OF PREMENSTRUAL SYNDROME (MUTLAZIMA QABL HAIZ ) IN UNANI SYSTEM OF MEDICINE
}

\author{
Dr. Sofia Naushin*1, Dr. Mubarak Ali ${ }^{1}$, Dr. Mustehasan ${ }^{2}$ \\ ${ }^{1}$ Research Associate, CCRUM, Ministry of Ayush, Govt. of India. \\ ${ }^{2}$ Research Officer, CCRUM, Ministry of Ayush, Govt. of India.
}

\begin{abstract}
Mutlazima Qabl Haiz (Premenstrual syndrome) refers to a combination of physical and emotional disturbances that occur after a woman ovulates and resolves with start of menstruation. More than 200 symptoms have been ascribed to PMS. Premenstrual Dysphoric Disorder is a more severe form of premenstrual syndrome. The characteristic symptoms of premenstrual syndrome are mood swings, anxiety, and irritability and physical conditions - like headache, fatigue, bloating, sleep disturbances, nausea, and breast tenderness. $90 \%$ of the women all over the world experience these symptoms during their reproductive years. The PMS has unknown cause and does not have any specific proved diagnosis and medication in modern medicine. The main objective of this article is to review the potential treatment for premenstrual syndrome in Unani medicine.
\end{abstract}

Keywords: Premenstrual Syndrome, Premenstrual Dysphoric Syndrome, Unani Management.

Article Info: Received 17 Sep, 2018; Review Completed 10 Oct 2018; Accepted 12 Oct 2018; Available online 15 Oct 2018

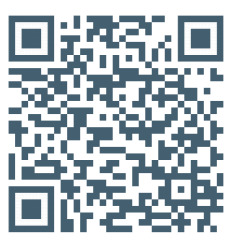

\section{Cite this article as:}

Naushin S, Ali M, Dr. Mustehasan, Concept and management of premenstrual syndrome (Mutlazima Qabl Haiz ) in unani system of medicine, Journal of Drug Delivery and Therapeutics. 2018; 8(5-s):122-125 DOI: http://dx.doi.org/10.22270/jddt.v8i5-s.1992

*Address for Correspondence:

Dr. Sofia Naushin, Research Associate, CCRUM, Ministry of Ayush, Govt. of India.

\section{INTRODUCTION}

The luteal phase of menstrual cycle starts from the time of ovulation and ends at the onset of menses. Some women experience physical, emotional and psychological symptoms during their luteal phase and beginning of their menstrual bleeding that are known as premenstrual syndrome. ${ }^{1}$ The psychological symptoms include irritability, mood swings, depressed mood, crying spells, low self-esteem, anxiety, sleep disturbance, increased appetite, lethargy or fatigue; cognitive symptoms include forgetfulness, decreased concentration and physical symptoms include breast tenderness, bloating, fluid retention, weight gain, constipation, hot flushes, headaches, musculoskeletal discomfort, acne, rhinitis, palpitation. ${ }^{2}$ Approximately $40 \%$ of women experience luteal phase symptoms during menstrual cycle that are troublesome; for $25 \%$ these are irritating but do not impair functioning; for 10$15 \%$, the symptoms are severe with significant impairment in daily life activities ${ }^{3,4}$ It has also been found that the prevalence of premenstrual syndrome (PMS) is higher in unmarried women, in women who belong to a low socioeconomic deprived areas and in women aged $35-44$ years. ${ }^{5-6}$

\section{SYMPTOMS OF PMS}

In 1931, Robert Frank used the term "Premenstrual Tension" for this phenomena. Greene and Dalton in 1953 called this condition as "Premenstrual Syndrome" to allow the inclusion of both somatic and psychological complaints in the symptom complex. ${ }^{7}$ Mutlazima Qabl Haiz is the term from the Arabic dictionary ${ }^{8,9}$ in which syndrome is translated as 'mutlazima', pre stands for 'qabl' and menstrual is the word given for 'haiz'. No such term was defined by ancient Unani scholars but they had given a description on premenstrual features. The ancient physicians mentioned that, imtelayi kaifiat present in the premenstrual phase which leads to number 
of features. It is well documented that surge of akhlat muharrika (hormones) are responsible for build up of body fluid in tissue spaces during premenstrual phase and this theory correlates with the concept given by IbnSina ${ }^{10}$ and others are as follows:

* According to Zakariya Razi symptoms are anorexia, lassitude, anxiety, tremers and when these symptoms increase in intensity person may also complain of pelvic pain, pica, headache, backache and vomiting. ${ }^{11}$

* According to Ghulam Jeelani and Hakeem Ajmal Khan, the functions of liver get disturbed as a result of circulation of toxins in the blood during premenstrual phase, so that the person is unable to bear minor degrees of disturbances which lead to palpitation, headache and giddiness. These persons show temperament changes of melancholic type. ${ }^{12,13}$

* According to Ibn Sina in Canon of Medicine under the heading of "Plethora (Imtila akhlat)" symptoms are anxiety, tension, headache, irritability, decreased concentration, insomnia, anorexia, palpitation, weight gain, food cravings, constipation, nausea, diarrhoea, puffiness of face, tingling in skin, and numbness in hand and leg. ${ }^{10}$

\section{ETIOLOGY OF PMS}

Although the underlying cause remains uncertain; seems to be multifactorial but ovarian hormone cycle appears to be important factor, since premenstrual syndrome is not observed before puberty in girls and after menopause in women. Some theories have been suggested to explain the pathophysiology of severe PMS as follows.

1. Ovarian hormone theory: The PMS is only observed in the women of reproductive age, it is supposed that the female gonadal hormones play a causative role, possibly mediated through the alteration of serotoninergic activity in the brain. This theory hypothesises that imbalance in the estrogen to progesterone ratio is the cause of PMS, with a relative deficiency in progesterone. ${ }^{15}$ Trial has shown that administration of progesterone hormone during the premenstrual phase of the menstrual cycle can decrease the severity of premenstrual symptoms in some women.

2. Deficiency of Neurotransmitter: This theory implicates the deficiency of neurotransmitters such as serotonin and gaminobutyric acid (GABA) as a cause of PMS. Serotonin receptors are responsive to estrogen and progesterone, and Serotonin deficiency has been postulated in PMS patients; as the symptoms of PMS respond to selective serotonin reuptake inhibitors (SSRIs), which increase the amount of circulating Serotonin. GABA levels are modulated by the, allopregnanolone, a metabolite of progesterone and in women with PMS the allopregnanolone levels appear to be reduced. ${ }^{17}$

\section{MANAGEMENT}

PMS is prevalent in women of reproductive age causing substantial morbidity with obvious detriment to interpersonal relationships, social interactions, lifestyle, work performance, emotional well-being and overall health-related quality of life. ${ }^{18}$ Treatment goals for PMS are to ameliorate or reduce symptoms, decrease their impact on daily activities and interpersonal relationships, and reduce adverse effects of treatment.

\section{Nonpharmacologic}

\section{* Diet}

The usual recommendations are for a decrease in salt, sugar, alcohol and caffeine, and an increase in meals with a low glycaemic index. It is suggested that an increased complex carbohydrate intake increases brain serotonin activity, which in turn improves symptoms.

\section{* Exercise}

Aerobic activity leads to increased endorphin levels, which are known to improve mood, and several studies recommend there may be some benefit in the treatment of PMS. ${ }^{19}$

\section{* Cognitive Behavior Therapy}

A 2009 meta-analysis analyzed seven trials, three of which were randomized controlled trials, and showed improvement in functioning and depression scores for patients with PMS or PMDD. ${ }^{20}$

\section{Pharmacologic:}

Pharmacologic therapies carry a greater risk of adverse events, and this must be considered when selecting such therapy, and should be only suggested to patients if symptoms are not adequately relieved by nonpharmacologic measures. ${ }^{21}$

* Serotonergic Antidepressants: Medications affecting serotonin are first-line treatment of choice for severe PMS or PMDD 22,23 The selective serotonin reuptake inhibitors (SSRIs) citalopram (Celexa), escitalopram (Lexapro), fluoxetine (Prozac), and sertraline (Zoloft) - taken every day or only during the luteal phase of menstruationsignificantly decrease physical and psychological symptoms of PMS compared with placebo. ${ }^{23}$

* Oral contraceptive pills (OCPs): Some women with the PMS are prescribed the OCPs to balance their ovarian hormones fluctuations. Research has reported that the new OCP formulations seem to be more beneficial and effective in the improvement of premenstrual symptoms. ${ }^{24,25}$

* Suppression of ovarian cycle: Gonadotropinreleasing hormone $(\mathrm{GnRH})$ analogues suppress ovarian function and reduce disturbing premenstrual symptoms in some women. ${ }^{26}$ However, it may not be used for more than six months due to its adverse effects, particularly hot flushes and decreased bone density. ${ }^{22}$ Androgenic agent like danazol inhibits gonadotropin release, thus improving mastalgia. ${ }^{27}$ Continuous danazol therapy may also relieve other PMS symptoms. However, long term therapy of 
danazol is limited by side effects such as masculinization (e.g., weight gain, decreased breast size, deepening of the voice), as well as adverse effects on LFTs and serum lipid profiles. ${ }^{27,28}$

3. Supplements: Certain supplements have been reported to be efficient in the reduction of the severity and duration of the premenstrual symptoms. They are calcium supplements $(1000 \mathrm{mg})^{29}$,magnesium $(200 \mathrm{mg})$ ${ }^{30}$, vitamin E (400 units), vitamin B6 (pyridoxine) ${ }^{31}$, chaste berry (vitex agnus castus) ${ }^{32}$, St John's Wort ${ }^{33}$, evening primrose oil (3000-4000 mg) ${ }^{26}$, Black Cohosh and Dandelion ${ }^{34}$. It has been reported that these therapies need to be taken for at least two consecutive cycles to be effective. ${ }^{16,29,30}$ High doses of supplements may be toxic and harm the liver in some individuals, so consult with their physicians before taking any supplements. ${ }^{35}$

\section{MANAGEMENT PROTOCOL OF PMS}

The following steps for treating PMS are based on recommendations outlined in an ACOG Practice Bulletin:

* Step 1:

A. Mild/moderate symptoms: Supportive therapy with good nutrition, complex carbohydrates, aerobic exercise, calcium supplements, and possibly magnesium or chaste berry fruit.

B. If physical symptoms predominate: NSAIDs or Spironolactone, or balance hormonal formulations with OCPs or medroxyprogesterone acetate.

\section{* Step 2:}

When mood symptoms are significantly impairing function then SSRI therapy is used. An anxiolytic like alprazolam can be used for such symptoms not relieved by the SSRI medication.

\section{* Step 3:}

If not responsive to above said treatment GnRH agonists is recommended. This would not be done in an adolescent without consultation with a gynaecologist. ${ }^{36}$

\section{UNANI TREATMENT}

There are different types of Unani medicines which are being prescribed for the treatment of premenstrual syndrome.

* According to Ibn Sena, the menstruation which occurs as a result of generalized edema is treated by venesection (fasd). He further mentioned that its treatment should be according to cause. If the cause is heat (hiddat) and dominance of bile then it is best treated by evacuation (istefragh) of bile especially by Shahtara (fumaria officinalis) and halela (Terminalia Chebula) because they both have astringent property also. If retention of fluid is the reason then it is excreted through skin by using drugs such as Samaghe arbi(Acacia Arabica) and Kateera (Sterculia Urens). If the cause is weakness of uterus then astringent drugs along with uterine tonics are prescribed. ${ }^{10}$

* Zakaria Al Razi described drugs having diuretic and emmenagogue properties and also included Jund bedaster (Castoreum), Tukhme Karafs (Apium Graveolens, Heel Kalan (Amomum Subulatum), Habbe Balsan (Commiphora Opobalsamum) in this group. ${ }^{11}$

* According to Ghulam Jeelani and Ajmal Khan following formulations having diuretic and emmenogogue actions are beneficial if used for 7 to 10 days before menstruation.

1. Gule Khatmi (Althaea Officinalis), Tukhme Turb (Raphanus Sativus), Mushktiramashi (Mentha Pulegium), Parsyaoshan (Adiantum Cappilus Veneris), Mako ( Solanum Nigrum), each 5 gram is taken and decoction is prepared to which $1 \mathrm{gm}$ Jawakhar (Pottasium carbonate) is added and used for 7 days before menstruation.

2. Sufoof Mudir Haiz is also useful which has the following ingredients: Revand chini (Rheum emodi), Shora qalmi (Pottasium Nitrate), Jawakhar (Pottasium Carbonate), Zeera Safaid (Cuminum Cyminum) and sugar each 12 grams is grinded to prepare fine powder and used as 7 grams. ${ }^{12,13}$

\section{CONCLUSION}

Premenstrual syndrome have unknown multifactorial causes but highly treatable disorders. Herbal medicines play important role for managing the symptoms of PMS. PMS affects the quality of life for many women of reproductive age. Pharmacological treatments having limited efficacy and substantial side effects. Lifestyle changes, dietary modifications, complementary therapies and prescription medications reduce the symptoms of premenstrual syndrome (PMS). Lifestyle changes include regular exercise, quit smoking, reduce intake of salt and caffeine and getting sufficient sleep. Dietary supplements are helpful in reducing symptoms of premenstrual syndrome. Some scientific studies prove the effectiveness of herbs to help reduce the effects of PMS and report relief of PMS symptoms with the use of herbs such as evening primrose oil and saffron. Unani can offer a great benefit to the female population by improving her psychosocial as well as physical health which ultimately contributes to a healthy society. 


\section{REFERENCES}

1. Wyatt K, Efficacy of vitamin B6 in the treatment of premenstrual syndrome: Systematic review. BMJ, 1999; 318:1375-1381.

2. Hantsoo L, Epperson CN. Premenstrual Dysphoric Disorder: Epidemiology and Treatment. Curr Psychiatry Rep. 2015; 17(11):87.

3. Johnson SR. Premenstrual Syndrome, Premenstrual Dysphoric Disorder and Beyond: A Clinical Primer for Practitioners. Obstet Gynecol 2004; 104(4):845-59

4. Sternfeld B, Swindle R, Chawla A, Long S, Kennedy S. Severity of Premenstrual Symptoms in a Health Maintenance Organization Population. Obstet Gynecol 2002; 99(6):101424.

5. Cheng $\mathrm{SH}$ et al.: Perception of premenstrual syndrome and attitude of evaluations of work performance among incoming university female students. Biomed J. 2015; 38:167-72.

6. Shershah S, Morrison JJ, Jafarey S. Prevalence of premenstrual syndrome in Pakistani women. J Pak Med Assoc. 1991; 41(5):101-3.

7. Copeland LJ, Jarrell JF, McGregor JA. Textbook of Gynaecology. Philadelphia: WB Saunders Company; 1993: 403-413.

8. www.languagesource.com/acatolog/Arabic_Translation_Soft ware_Arabic_Al_Wafi.html. cited on 27.06.16.

9. Anonymous. The Unified Medical Dictionary. Eng-AraFren.3rd ed. Switzerland: Council of Arab ministers of health; 1983:642.

10. IbnSina. Al Qanoon Fil Tib. Vol II. (Urdu Translation by Kantori GH). New Delhi: Idarae Kitabus Shifa; 1981: 331345 .

11. Zakari Razi. (2001) Kitaul Havi Vol $9^{\text {th }}$. New Delhi; CCRUM .p.151-168.

12. Ghulam Jeelani. Makhzan-e-Hikmat, Vol II, Mufeed Aam Press, Lahore. 1933: p-1928-1932.

13. Ajmal khan. (1983) Hazique New Delhi Jaseen Book Depo: p. 461-471.

14. Emans SJ, Laufer MR, Goldstein DP. Premenstrual syndrome. Pediatric and Adolescent Gynecology. 5th ed. Philadelphia, PA: Lippincott-Raven Inc; 2005. 461-467.

15. Cunningham J, Yonkers KA, O'Brien S, Eriksson E. Update on research and treatment of premenstrual dysphoric disorder. Harv Rev Psychiatry, 2009; 17(2):120-137.

16. Khajehei M, Abdali K, Parsanezhad ME, Tabatabaee HR. Effect of treatment with dydrogesterone or calcium plus vitamin $\mathrm{D}$ on the severity of premenstrual syndrome. Int $\mathbf{J}$ Gynaecol Obstet. 2009; 105(2):158-161.

17. Roger P. smith. Gynaecology in primary care. Philadelphia: Williams and Wilkins; 1997: 427-441.

18. Paula K.B., Mini-Review: Premenstrual Syndrome and Premenstrual, Dysphoric Disorder. Journal of Pediatric and Adolescent Gynecology. 2007; 20:3-12

19. Brian Magowan Philip Owen Andrew Thomson. Clinical Obstetrics and Gynecology $3^{\text {rd }}$ Edition; 2014.

20. Lustyk MK, Gerrish WG, Shaver S, Keys SL. Cognitivebehavioral therapy for premenstrual syndrome and premenstrual dysphoric disorder: a systematic review. Arch Womens Ment Health. 2009; 12(2):85-96.

21. Elena A.Q. , Ghassan A.Q., Does Vitamin D and Calcium Affect the Incidence of Premenstrual Syndrome, World family medicine journal. 2010; 7(10).

22. American College of Obstetricians and Gynecologists. ACOG practice bulletin no. 15: Premenstrual syndrome. Obstet Gynecol. 2000; 95(4).

23. Brown J, O'Brien PM, Marjoribanks J, Wyatt K. Selective Serotonin Reuptake Inhibitors for Premenstrual Syndrome. Cochrane Database Syst Rev. 2009; 15(2):CD001396.

24. Yonkers KA et al. Efficacy of a New Low-Dose Oral Contraceptive With Drospirenone in Premenstrual Dysphoric Disorder. Obstet Gynecol. 2005; 106(3):492-501.

25. Lopez L, Kaptein A, Helmerhorst FM. Oral Contraceptives Containing Drospirenone for Premenstrual Syndrome. Cochrane Database Syst Rev. 2008; 23(1):CD006586.

26. Rapkin A. A Review of Treatment of Premenstrual Syndrome \& Premenstrual Dysphoric Disorder. Psychoneuroendocrinology. 2003; 28(Suppl 3):39-53.

27. O'Brien PM, Abukhalil IE. Randomized Controlled Trial of the Management of Premenstrual Syndrome and Premenstrual Mastalgia using Luteal Phase-Only Danazol. Am J Obstet Gynecol 1999; 180(1 pt 1):18-23.

28. Wyatt K, Dimmock PW, O'Brien PM. Premenstrual syndrome. In: Clinical evidence. Barton $\mathrm{S}$, ed. 4th issue. London: BMJ Publishing Group, 2000:1121-33.

29. Ward M, Holimon T. Calcium Treatment for Premenstrual Syndrome. Ann Pharmacother 1999; 33(12):1356-1358.

30. Shamberger RJ. Calcium, magnesium, and other elements in the red blood cells and hair of normals and patients with premenstrual syndrome. Biol Trace Elem Res. 2003; 94(2):123-9.

31. Bendich A. The Potential for Dietary Supplements to Reduce Premenstrual Syndrome (PMS) Symptoms. J Am Coll Nutr. 2000; 19(1):3-12.

32. Loch E, Selle H, Boblitz N. Treatment of Premenstrual Syndrome with a Phytopharmaceutical Formulation Containing Vitex agnus castus. J Womens Health Gend Based Med. 2000; 9(3):315-20.

33. Szegedi A, Kohnen R, Dienel A, Kieser M. Acute Treatment Of moderate to Severe Depression with Hypericum Extract WS 5570 (St John's wort): Randomised Controlled Double Blind Non-inferiority Trial versus Paroxetine. BMJ. 2005; 330(7490):503. Epub 2005 Feb 11

34. Liu $\mathbf{J}$ et al. Evaluation of Estrogenic Activity of Plant Extracts for the Potential Treatment of Menopausal Symptoms. J Agric Food Chem. 2001; 49(5):2472-9.

35. Navarro $\mathrm{V}$ et al. Liver injury from herbals and dietary supplements in the U.S. Drug-Induced Liver Injury Network. Hepatology. 2014; 60(4):1399-408. doi: 10.1002/hep.27317. Epub 2014 Aug 25.

36. Paula K. B., Mini-Review: Premenstrual Syndrome and Premenstrual, Dysphoric Disorder. Journal of Pediatric and Adolescent Gynecology. 2007; 20:3-12. 